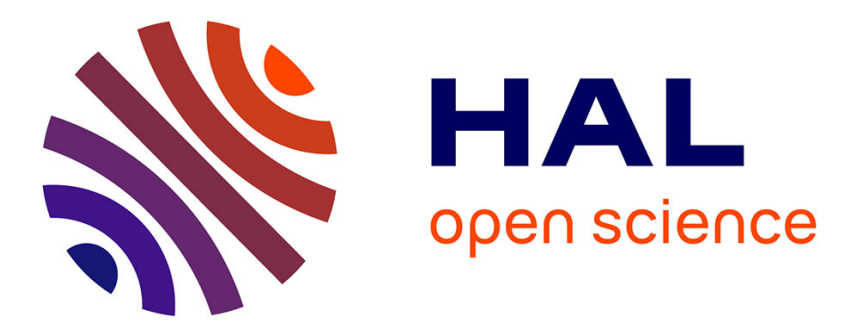

\title{
Spiro-configured phenyl acridine thioxanthene dioxide as a host for efficient PhOLEDs.
}

Maxime Romain, Denis Tondelier, Bernard Geffroy, Anna Shirinskaya, Olivier Jeannin, Joëlle Rault-Berthelot, Cyril Poriel

\section{- To cite this version:}

Maxime Romain, Denis Tondelier, Bernard Geffroy, Anna Shirinskaya, Olivier Jeannin, et al.. Spiroconfigured phenyl acridine thioxanthene dioxide as a host for efficient PhOLEDs.. Chemical Communications, 2015, 51 (7), pp.1313-5. 10.1039/C4CC08028A . hal-01114444

HAL Id: hal-01114444

https://hal-univ-rennes1.archives-ouvertes.fr/hal-01114444

Submitted on 14 Sep 2015

HAL is a multi-disciplinary open access archive for the deposit and dissemination of scientific research documents, whether they are published or not. The documents may come from teaching and research institutions in France or abroad, or from public or private research centers.
L'archive ouverte pluridisciplinaire HAL, est destinée au dépôt et à la diffusion de documents scientifiques de niveau recherche, publiés ou non, émanant des établissements d'enseignement et de recherche français ou étrangers, des laboratoires publics ou privés. 


\section{Spiro-configured Phenyl Acridine Thioxanthene Dioxide as host for efficient PhOLEDs}

Maxime Romain,a Denis Tondelier,b Bernard Geffroy,b,c Anna Shirinskaya,b Olivier Jeannin,a Joëlle Rault-Berthelota and Cyril Poriela*

A new high triplet organic semi-conductor based on a Donor-Spiro-Acceptor design has been synthesised and used as host material in high performance $(E Q E=11.4 \%)$ sky blue Phosphorescent Organic Light Emitting Diodes.

Phosphorescent Organic Light-Emitting Diodes (PhOLEDs), which use heavy-metal complexes dispersed in a host material as emitters (to harvest both singlet and triplet excitons) have attracted fantastic interest for the last fifteen years. ${ }^{1-3}$ However, blue PhOLEDs remain the weakest link of the technology in term of stability and efficiency, mainly because of the lack of highly efficient host materials. ${ }^{3-5}$ In this context, the chemical design of organic hosts is of great importance and the prerequisites are (i) a high $E_{\mathrm{T}}$ to prevent reverse energy transfers from the guest back to the host and confine triplet excitons on guest molecules, (ii) a high glass-transition temperature (Tg) and decomposition temperature (Td) for device stability, (iii) matching HOMO-LUMO levels for hole and electron injection (iv) good and balanced charge transporting properties to insure efficient recombination in the guest. In addition, a very simple molecular structure, which can be easily synthesized, is also a key feature for mass production. Bipolar molecules incorporating hole and electron transporting units are to date the most promising candidates. ${ }^{3,4,6-9}$ Numbers of efficient approaches have been developed to gather all the above mentioned properties in a single host, most of them being based on a $\pi$-conjugation disruption in order to obtain the spatial separation of HOMO and LUMO levels. In the present work, we wish to report a very simple molecular design based on a $\pi$ conjugation breaking induced by an insulating spiro bridge between an efficient hole transporting unit, that is a phenyl acridine moiety ${ }^{10}$ and a very barely studied electron transporting moiety that is thioxanthene dioxide (Scheme 1). Thioxanthene dioxide is the analogue of xanthene and possesses a sulfone unit instead of the intracyclic oxygen atom, leading to better electron injection and transport abilities due to the depress of the LUMO level. ${ }^{11}$ This ability has been poorly studied to date in organic electronics and this is the property we want to exploit herein. Due to the spiro bridge, the Donor-Spiro-Acceptor design allows to perfectly separate HOMO and LUMO levels retaining a very high $\mathrm{E}_{\mathrm{T}}, 3.08 \mathrm{eV}$, and good physical properties. Such design has started to appear for the last two years due to its great potential in Thermo Activated Delayed Fluorescence ${ }^{12,13}$ but remains almost absent to date for hosting phosphorescent dopants. ${ }^{14,15}$ This work reports hence an efficient host material SPA-TXO $\mathbf{O}_{2}$ based on this promising design, leading to high performance green and sky blue PhOLEDs (EQE of 14.8 and $11.4 \%$ respectively). This work is also, to the best of our knowledge, the first example of a spirothioxanthene dioxide dye and may pave the way to the development of hosts based on this electron accepting moiety.

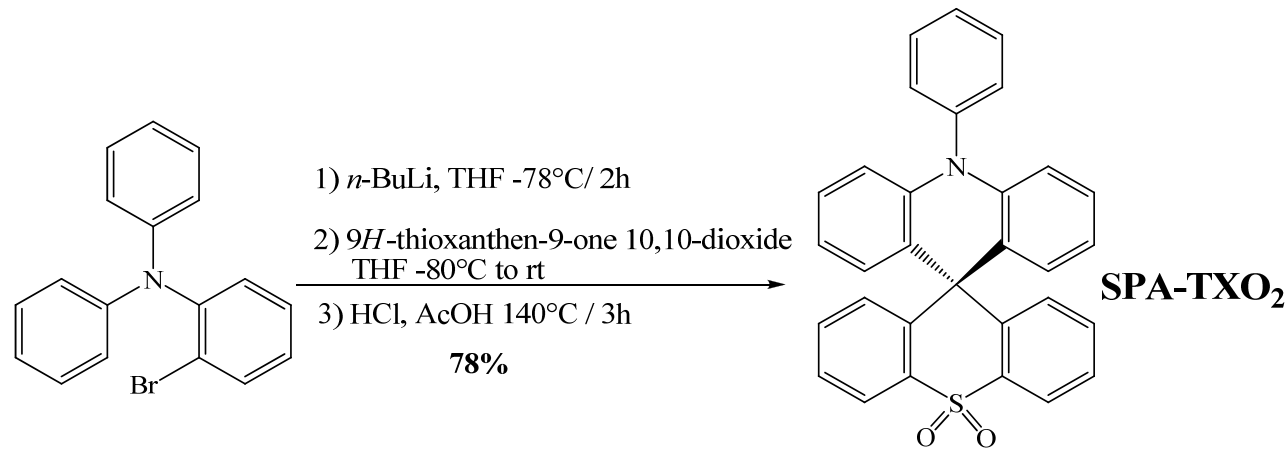

Scheme 1. Synthesis of SPA-TXO 
SPA-TXO $\mathbf{O}_{2}$ has been synthesized in an efficient one pot three step approach (Scheme 1). A lithiumbromine exchange was first performed on 2-bromophenyldiphenylamine followed by the trapping of the lithiated intermediate by $9 H$-thioxanthen-9-one 10,10-dioxide. Electrophilic intramolecular cyclisation of the resulting alcohol (not isolated) in acidic media afforded 10-phenyl-10 $\mathrm{H}$-spiro[acridine-9,9'thioxanthene] 10',10'-dioxide SPA-TXO $\mathbf{O}_{2}$ in high yield (78\% over the three steps). This short and very efficient synthetic approach easily allows a gram-scale preparation and purification, key feature for further device fabrication.
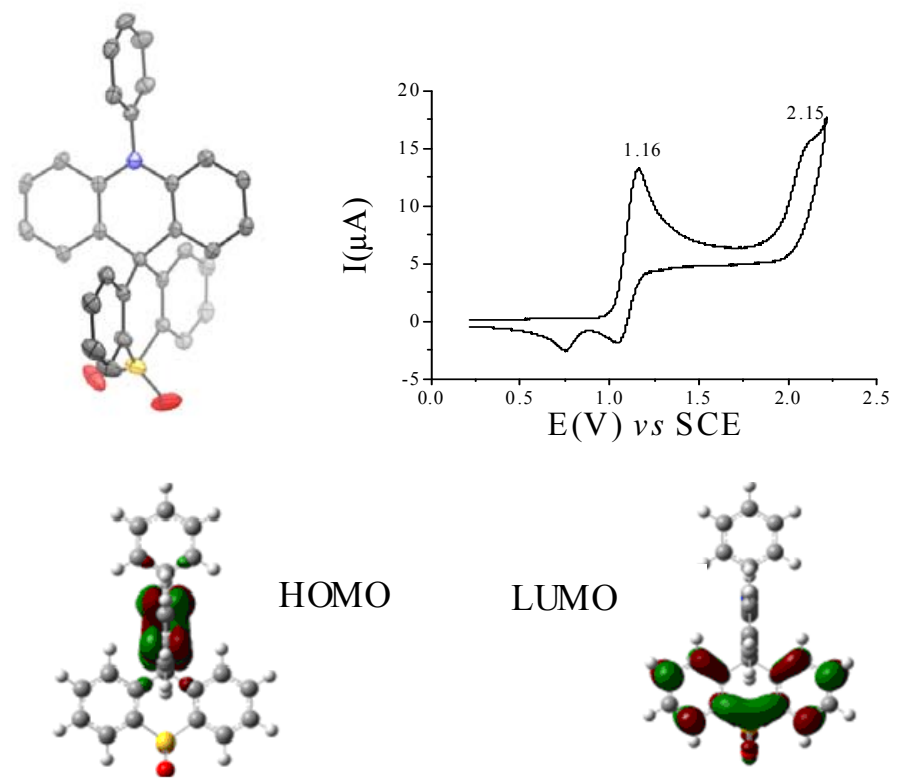

Fig 1. Top. ORTEP drawing (left, $50 \%$ ellipsoid probability) and cyclic voltammetry $\left(100 \mathrm{mV}^{-\mathrm{s}^{-1}}\right)$ in $\mathrm{CH}_{2} \mathrm{Cl}_{2} /\left[\mathrm{NBu}_{4}\right]-$ $\left[\mathrm{PF}_{6}\right]$ 0.2M (right) of SPA-TXO $\mathbf{O}_{2}$. Bottom: Calculated nature of the highest occupied (HOMO) and lowest

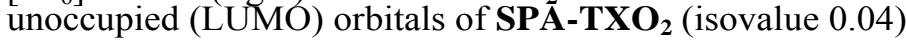

The molecular structure of SPA-TXO $\mathbf{O}_{2}$ has been confirmed by X-ray diffraction on single crystals (Fig. 1, top-left). The molecule radius (distance from the spiro carbon atom to the farthest carbon atom) has been evaluated at $7.14 \AA$. The thioxanthene dioxide and acridine fragments are almost orthogonal with a twist angle of $88^{\circ}$ (identical to the angle between N-phenyl and acridine unit). This structural feature is at the origin of the absence of significant $\pi$-conjugation between the two fragments that will be described below. Thus, the present spiro acridine/thioxanthene structure is not more twisted than other spirobifluorene derivatives ${ }^{16}$ highlighting the potential of this building block to obtain shape persistent molecules with orthogonal configuration. ${ }^{17}$ In addition, the acridine and thioxanthene dioxide fragments have a dihedral angle between the two external benzene rings of respectively $3.3^{\circ}$ and $11.5^{\circ}$. This shows that dihydroacridine keeps a flat structure while the thioxanthene dioxide is slightly twisted.

The electrochemical behaviour of SPA-TXO $\mathbf{T}_{2}$, investigated by cyclic voltammetry (Fig. 1, top right) consists of two oxidation waves with maxima at $\mathrm{E}^{1}=1.16 \mathrm{~V}$ and $\mathrm{E}^{2}=2.15 \mathrm{~V}$. The first oxidation wave, attributed to the oxidation of the phenylacridine unit, appears partially reversible, highlighting some reactivity of the phenylacridine radical-cation at the voltammetry time scale. The reversibility of the first wave can be obtained at a sweep rate of $2 \mathrm{~V} / \mathrm{s}$ (see SI). In the cathodic range, no clear reduction wave was observed and only the onset potential has been detected (see SI). In the light of the character of the HOMO and LUMO level determined with Density Functional Theory (DFT) at the Gaussian09 B3LYP/6$311+\mathrm{G}(\mathrm{d}, \mathrm{p})$ level of theory, the first electron transfer in oxidation resp. reduction was centered on the acridine resp. thioxanthene dioxide unit (Fig. 1, bottom). Indeed, the spatial distribution of the electron density of HOMO is confined on the acridine moiety whereas that of LUMO is confined on thioxanthene dioxide moiety. Thus, the spiro bridge induces a $\pi$-conjugation disruption leading to the complete spatial 
separation of HOMO and LUMO, which is highly beneficial to keep a high triplet state energy level (see below). From the onset oxidation/reduction potentials, HOMO and LUMO were estimated to lie around $5.43 \mathrm{eV}$ and $-2 \mathrm{eV}$, leading to an electrochemical gap $\Delta \mathrm{E}^{\mathrm{el}}$ of $3.43 \mathrm{eV}$. Despite a slight deviation, the calculated HOMO/LUMO energy differences $\left(\Delta \mathrm{E}^{\mathrm{cal}}=4.13 \mathrm{eV}, \mathrm{HOMO} / \mathrm{LUMO}:-5.57 /-1.44 \mathrm{eV}\right)$ are consistent with the electrochemical data. Compared to structurally related phenylacridine compounds bridged by a spiroanthracenone (HOMO/LUMO: $-5.50 /-1.90 \mathrm{eV})^{14}$ or by two phenyls units (HOMO/LUMO: -5.42/-1.74 eV), ${ }^{14}$ SPA-TXO ${ }_{2}$ possesses an almost identical HOMO level, $-5.43 \mathrm{eV}$ due to the presence of the phenylacridine, but a lower LUMO energy level, $-2 \mathrm{eV}$. This highlights the efficiency of the present design, which allows selectively tuning the LUMO energy level without altering that of the HOMO.

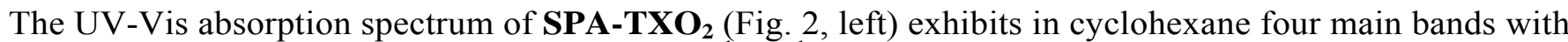
low absorption coefficients around $5000 \mathrm{~L} \cdot \mathrm{mol}^{-1} \cdot \mathrm{cm}^{-1}$. This is consistent with the presence of small and weakly conjugated units. Time-dependent density functional theory (TD-DFT) calculations performed at the Gaussian09 B3LYP/6-311+G(d,p) level of theory highlight that the HOMO-LUMO transition possesses an oscillator strength close to zero $(\mathrm{f}=0.0001$, see $\mathrm{SI})$, due to the absence of significant overlap between the HOMO and LUMO. Thus, the UV-Vis absorption spectrum does not show any additional band except those of the two independent fragments, clearly indicating that there is no significant conjugation between the acridine and thioxanthene units.
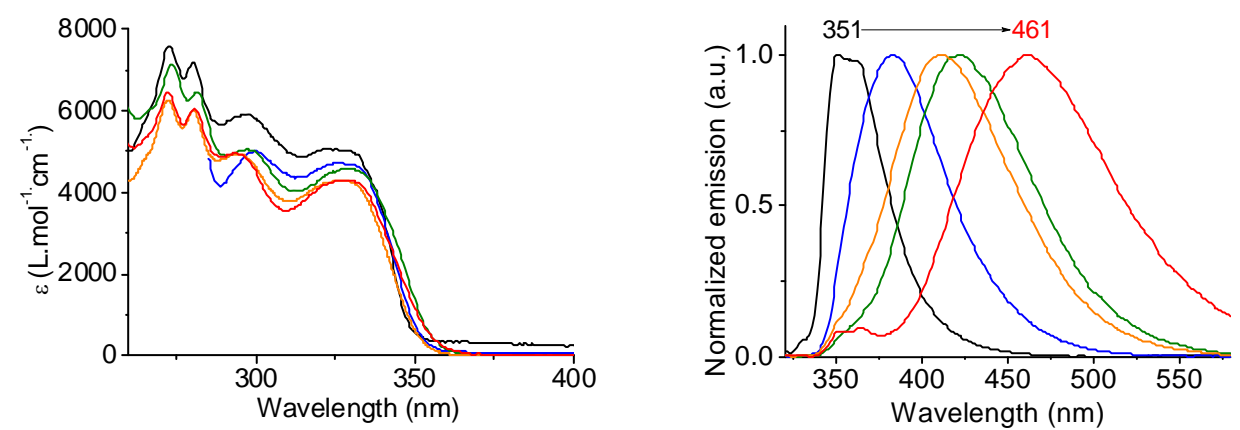

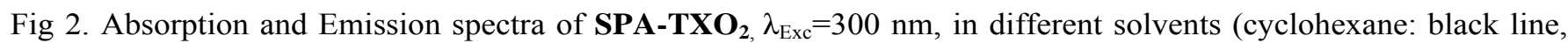
toluene: blue line, chloroform: green line, ethyl acetate: orange line, acetonitrile: red line).

From a careful inspection of the dependence of the absorption behaviour of SPA-TXO $\mathbf{S}_{2}$ on solvent polarity (Fig. 2-left), we note that the absorption maximum is almost insensitive to the dielectric constant of the environment. This indicates that the electronic and structural characteristics of the ground and FranckCondon excited states do not differ much with a change in solvent polarity. ${ }^{18}$ Oppositely, the fluorescence spectra reveal a clear solvatochromic effect (Fig. 2-right). Indeed, SPA-TXO $\mathbf{O}_{2}$ is highly sensitive to the solvent polarity with fluorescence maxima ranging from $351 \mathrm{~nm}$ in cyclohexane to $461 \mathrm{~nm}$ in acetonitrile. This impressive dependence of the emission wavelength (red shift of $110 \mathrm{~nm}$ ) on the solvent polarity is the consequence of dipole-dipole interactions between SPA-TXO $\mathbf{O}_{2}$ and polar solvent molecules and hence of a photoinduced intramolecular charge transfer (ICT) between the donor and the acceptor in the excited state. In addition, a very large $\Delta \mu$ of $32.6 \mathrm{D}$ has been evaluated using Lippert Mattaga formalism (dipole moment at the ground state obtained through DFT calculations: $\mu\left(S^{0}\right)=7.5 \mathrm{D}$, dipole moment at the excited state: $\mu\left(\mathrm{S}^{1}\right)=40.1 \mathrm{D}$, see SI) indicating significant ICT characteristics in the excited state. Increasing the solvent polarity tends hence to stabilize the ICT excited state relative to the ground state, leading to an energy gap extension and hence to a large bathochromic shift of the fluorescence maximum. Another important feature on the photophysics of the present dye is related to its emission processes. Indeed, due to the orthogonal configuration of SPA-TXO $\mathbf{O}_{2}$, the fluorescence emission occurs by a through-space charge transfer. This through-space interaction leads to a very low quantum yield (ca $6 \%$ in cyclohexane and even lower in all the solvents tested, see SI) perfectly matching with the TD-DFT calculations. At $77 \mathrm{~K}$, the emission spectrum of SPA-TXO $\mathbf{O}_{2}$ (in a mixture of methylcyclohexane and 2-methylpentane:1/1) presents a well-resolved phosphorescence contribution, characteristic of very rigid molecular structure, constituted of 
two maxima recorded at 402 and $430 \mathrm{~nm}$ (see SI). The corresponding $\mathrm{E}_{\mathrm{T}}$ obtained by the highest-energy phosphorescent peak was thus estimated at ca $3.08 \mathrm{eV}$. This very high $\mathrm{E}_{\mathrm{T}}$ appears promising for PhOLED application. Before any possible OLED application and in order to confirm the efficiency of the present chemical design, SPA-TXO $\mathbf{O}_{2}$ has been studied by thermogravimetric analyses (TGA) and differential scanning calorimetry (DSC), see SI. Due to the presence of the spiro bridge, SPA-TXO $\mathbf{O}_{2}$ is highly thermally stable with a decomposition temperature $\mathrm{T} d$ recorded at $313^{\circ} \mathrm{C}$ and no transition phase (melting, crystallization or glass transition Tg) was detected by DSC. Such thermal behaviour is of great importance to improve the lifetime and electroluminescence stability of OLEDs.

Finally, due to its very high $\mathrm{E}_{\mathrm{T}}$, SPA-TXO $\mathbf{O}_{2}$ has been used as host for phosphorescent green $\left(\operatorname{Ir}(\mathrm{ppy})_{3}, \mathrm{E}_{\mathrm{T}}=\right.$ $2.42 \mathrm{eV}$ ) and sky blue (FIrpic, $\mathrm{E}_{\mathrm{T}}=2.64 \mathrm{eV}$ ) dopants in PhOLEDs (see structure and performance of the devices in SI). The best performance of green PhOLEDs has been obtained with $9 \%$ of $\operatorname{Ir}(\mathrm{ppy})_{3}$. The device emits light at a very low voltage of $2.5 \mathrm{~V}$, with a maximum Current Efficiency (CE) as high as 62.0 $\mathrm{cd} / \mathrm{A}$ and a maximum Power Efficiency (PE) of $38.4 \mathrm{~lm} / \mathrm{W}$ (both recorded at $1 \mathrm{~mA} / \mathrm{cm}^{2}$ ). The External Quantum Efficient (EQE), determined at $10 \mathrm{~mA} / \mathrm{cm}^{2}$ is $14.8 \%$ (corresponding $\mathrm{CE}=54.9 \mathrm{~cd} / \mathrm{A}$ and $\mathrm{LE}=26.8$ $\mathrm{Lm} / \mathrm{W}$ ). More importantly, sky blue PhOLEDs (see SI) with SPA-TXO ${ }_{2}$ as host (FIrpic: $26 \%$ ) present a very low threshold voltage below $3 \mathrm{~V}(2.9 \mathrm{~V})$ and maximum $\mathrm{CE}$ and $\mathrm{PE}$ of respectively $30.1 \mathrm{~cd} / \mathrm{A}$ and 19.8 $\mathrm{Lm} / \mathrm{W}$ (both recorded at $1 \mathrm{~mA} / \mathrm{cm}^{2}$ ). The EQE at $10 \mathrm{~mA} / \mathrm{cm}^{2}$ is as high as $11.4 \%$ (corresponding $\mathrm{CE}=$ $28.4 \mathrm{~cd} / \mathrm{A}$ and $\mathrm{LE}=14.4 \mathrm{Lm} / \mathrm{W}$ ). The corresponding electroluminescent spectrum (See SI) shows exclusively the emission of the phosphorescent emitter FIrpic, meaning (i) that the energy transfer cascade is highly efficient and (ii) that there is a good confinement of excitons in the emissive layer. In order to really evaluate the efficiency of the present host SPA-TXO $\mathbf{S}_{2}$, similar devices with the same architecture but using a benchmark well known and efficient host, ie N,N-dicarbazolyl-3,5-benzene (mCP, $\left.\mathrm{E}_{\mathrm{T}}: 2.9 \mathrm{eV}\right)^{4}$ have been also fabricated. Thus, an emissive layer constituted of $\mathbf{m C P}$ doped with FIrpic leads to a device with an EQE of $8.6 \%$ (at $10 \mathrm{~mA} / \mathrm{cm}^{2}$ ) and a threshold voltage of $3.2 \mathrm{~V}$ (see SI). With a higher threshold voltage of $0.3 \mathrm{~V}$ and an EQE lowered by $2.8 \%$, this benchmark mCP-based device clearly highlights the efficiency of SPA-TXO $\mathbf{X}_{2}$ based-OLEDs presented above. This performance indicates the efficiency of the present design and the potential of the thioxanthene dioxide as accepting unit.

In summary, we have synthesized, via a one pot approach, a new highly efficient host, SPA-TXO ${ }_{2}$, for PhOLED applications. The chemical design called Donor-Spiro-Acceptor is based on a $\pi$-conjugation breaking induced by an insulating spiro bridge between a hole transporting unit, that is acridine moiety and a new and promising electron transporting unit that is thioxanthene dioxide. This design allows a spatial separation of HOMO and LUMO, retaining nevertheless a very high $\mathrm{E}_{\mathrm{T}}(3.08 \mathrm{eV})$ and excellent physical properties. The performance of SPA-TXO $\mathbf{O}_{2} /$ FIrpic based devices is high (EQE of $11.4 \%$ at $10 \mathrm{~mA} / \mathrm{cm}^{2}$ for a LE of ca $28.4 \mathrm{~cd} / \mathrm{A}$ ), with a low threshold voltage, clearly highlighting the efficiency of the design and of the thioxanthene dioxide to obtain highly efficient hosts. Tuning the nature of spiroconnected electron/hole transporting moieties may pave the way to the development of such materials for highly efficient PhOLEDs.

We wish to thank the CDIFX and the C.R.M.P.O (Rennes), the CINES (Montpellier), the Institut des Sciences Analytiques (Villeurbanne), the Service de Microanalyse-CNRS (Gif sur Yvette), the Region Bretagne and the ADEME for a studentship (MR), and the ANR (n¹1-BS07-020-01) for financial support.

\footnotetext{
Notes and references

a UMR CNRS 6226 "Institut des Sciences Chimiques de Rennes" Université de Rennes 1-Campus de Beaulieu-35042 Rennes, cedex (France) Tel:(+33)2-2323-5977 E-mail: cyril.poriel@univ-rennes1.fr

b.UMR 7647, LPCIM, Ecole Polytechnique, 91128 Palaiseau, France

c. LICSEN/IRAMIS/NIMBE, CEA Saclay, 91191 Gif Sur Yvette, France
}

Electronic Supplementary Information (ESI) available: [Synthetic procedures, full characterization of SPA$\mathbf{T X O}_{2}, 1 \mathrm{D} / 2 \mathrm{D}$ NMR, copies of NMR spectra, computational details and devices fabrication /characterizations.]. See DOI: 10.1039/c000000x/

1 M. A. Baldo, D. F. O'Brien, Y. You, A. Shoustikov, S. Sibley, M. E. Thompson, S. R. Forrest, Nature 1998, 395, 151.

2 L. Xiao, Z. Chen, B. Qu, J. Luo, S. Kong, Q. Gong, J. Kido, Adv. Mater. 2011, 23, 926. 
3 Y. Tao, C. Yang, J. Qin, Chem. Soc. Rev. 2011, 40, 2943.

4 K. S. Yook, J. Y. Lee, Adv. Mater. 2012, 24, 3169.

5 S. Thiery, D. Tondelier, C. Declairieux, G. Seo, B. Geffroy, O. Jeannin, J. Rault-Berthelot, R. Métivier, C. Poriel, J. Mater. Chem. C 2014, 2, 4156.

6 R. Mondal, W.-Y. Hung, Y.-H. Chen, M.-H. Cheng, K.-T. Wong, Chem. Eur. J. 2013, 19, 10563.

7 B. Pan, B. Wang, Y. Wang, P. Xu, L. Wang, J. Chen, D. Ma, J. Mater. Chem. C 2014, 2, 2466.

8 C.-W. Lee, J. Y. Lee, Chem. Commun. 2013, 49, 1446.

9 C. Han, Z. Zhang, H. Xu, G.-H. Xie, R. Chen, Y. Zhao, W. Huang, Angew. Chem. Int. Ed. 2012, 122, 10251.

10 Y.-X. Zhang, L. Zhang, L.-S. Cui, C.-H. Gao, H. Chen, Q. Li, Z.-Q. Jiang, L.-S. Liao, Org. Lett. 2014, 16, 3748.

11 L. Yao, S. Sun, S. Xue, S. Zhang, X. Wu, H. Zhang, Y. Pan, C. Gu, F. Li, Y. Ma, J. Phys. Chem. C 2013, 14189.

12 G. Méhes, H. Nomura, W. Zhang, T. Nakagawa, C. Adachi, Angew. Chem. Int. Ed. 2012, 51, 11311.

13 Y. Im, J. Y. Lee, Chem. Mater. 2014, 26, 1413.

14 C.-J. Lin, H.-L. Huang, T. Mei-Rurng, C.-H. Cheng, J. Display. Tech. 2009, 5, 236.

15 C. Fan, Y. Chen, Z. Liu, Z. Jiang, C. Zhong, D. Ma, J. Qin, C. Yang, J. Mater. Chem. C 2013, 1, 463.

16 F. Moreau, N. Audebrand, C. Poriel, V. Moizan-Baslé, J. Ouvry, J. Mater. Chem. 2011, 21, 18715.

17 M. Romain, D. Tondelier, J.-C. Vanel, B. Geffroy, O. Jeannin, J. Rault-Berthelot, R. Métivier, C. Poriel, Angew. Chem. Int. Ed. 2013, 52, 1147.

18 Y. Ooyama, G. Ito, K. Kushimoto, K. Komaguchi, I. Imae, Y. Harima, Org. Biomol. Chem. 2010, 8, 2756. 